\title{
Image Study of Decorative Color in Visual Context
}

\author{
Yan Pei \\ New Media Art Department \\ National Academy of Chinese Theatre Arts \\ Beijing, China
}

\begin{abstract}
People in their lives are inseparable from the color all the time, color is the most active and most impact element of all the visual elements. Color used in all walks of life, it not only has an irreplaceable role in the field of decorative art, but also plays an important role in film and television works. This article starts from the decorative color features in video works and its presentation mode, use these as the basis to understanding and learning decorative colors in video works, and sum up the importance of decorative color for video work. The study on the effect of decorative color in video works will improve our rational understanding of the visual context.
\end{abstract}

Keywords-decorative color; visual context

\section{INTRODUCTION}

When color images became the main part of screen space, the film becomes more vivid, video work color has become an important part of the video work language since then, it not only has the representation function to restore the natural reality, but more importantly, it has expression function to convey the creation idea of the creator. In life, color is present in every corner of the world. Color confers the soul to objects, it is a symbol of emotion, people express their emotions, feelings and desires with color. In video works, color is a language, a kind of power, it can cause a variety of emotional expression and association, and has its own character and symbolic meaning. As a symbolic meaning, when a color establishes a close relationship with associated things, shows some special significance, and is recognized by people or spread in the community, it forms symbolic meaning of this color associated with certain things. Similarly, the specific visual decorative color on the screen refers to abstract general visual context which beyond representative content and arouse the audience to imagine the world which never seen before. The use of decorative colors in successful video works, their emotional expression and symbolism are inextricably linked, some decorative colors must convey emotions the hero or director is bound to express, and some emotional expressions often need the help of the color symbolism. Whether independent color symbol in video works, or a symbol of the local scene, also the overall tone symbol, decorative color should match the emotions expressed in the video works.

\section{THE AUthenticITy OF DECORATIVE COLOR}

Marcel Mardan said: the true invention of color film should from the day the directors know the following facts, which is color is not necessarily to be true (fully consistent with reality), it must first according to the value of different tones (such as black and white) and drama and psychological meanings (cool and warm color) to use color.

Decorative color performance is in accordance with the form laws of aesthetics which is author's subjective knowledge and experience, describe things with decorative techniques creation performance. It is a meaningful form, use lines, colors, forms, and other elements to provide people aesthetic pleasure, at the same time meet people's culture, ideals, symbolic, history and other deeper spiritual needs. The formal beauty of decorative color on one hand it has design-conscious, on the other hand it as "the most common art", rooted in the life and the broad masses of the people over a long period of time, and it has always been loved by the people.

When the sudden emergence of video art in many art categories, more and more audiences are no longer satisfied with blindly indulge in the plot infatuation, they paid more attention to the Ontology Language of image color in the visual context. "Color can convey the essence of each thing, and in the meantime with a strong passion", and decorative color as one of the most important design element, it shows more and more unique styling features and visual glamours in the video visual context. During video creation process, the creator not only can reproduction color objectively, but also can reconstruct a color according to the story demand in order to make it an essential organic ingredient in visual context , and it will be the element of visual language for character shaping and character psychology performance. "Color film appeal for color, just like the silent film appeal for sound", as Soviet film scientist Eisenstein talks about the color of the film she says. From here we can see the importance of decorative color in video works. Video is the art of light and shadow, weather the decorative color has been used appropriately, it directly affect the expression of the video work content.

\section{A. Cultural Authenticity of Decorative Colors}

Decorative color in video works, as one way of audiovisual narration, it severely restricted by the real image, and strived to reach the cultural authenticity. Decorative colors here, refers to a characterization to describe the actual state of matters, it is some kind of objective nature. This requires the use of decorative color in works to convey beauty, excited mood, create atmosphere, simple and accurate selection of the decorative colors which fit for the film theme and emotions. Because the decorative color is severely restricted by the real image, so it is the important aesthetic object for the audience to understand the film. In addition, the decorative color strive to 
reach the cultural authenticity, this cultural authenticity is a reality which has certain meaning of true and false, it expressed the real society and spiritual nutrient which drawn by human cognition into the assumed situation, it is a special aesthetic reality. The reason why it is assumed reality is because the use of these colors is not entirely in accordance with the historical context order, but it fit for the aesthetic rule of objective things, it is the inherent necessary feature of integrality and unity of the video itself.

This culture authenticity gives film artists with great creation space, such as Spanish photographer Armand, all of his works were focus on cultural authenticity of decorative color. Researchers specially studied this photographer's photography style and they have got the conclusion: "His film color all according to the evidence, "The story of Adele Hugo "imitated calm dark shades of classical painting," Kramer vs. Kramer "used simple bright gray color to recurring contemporary middle-class family living in New York, "New York stories" used a strong color contrast to highlight painter's passion, "The days of heaven" used flying clear colors to brew nostalgic poetry and so on. "His bright, dim, calm or flying decorative colors were the biggest feature of his films, which is objective and reality, strive to a cultural authenticity. Another example is the French director Jean - Jacques Arnold's film "Stalingrad: Enemy at the Gates", the German major's room was decorated in cool colors to display environment space, neat but cold; the Soviet soldiers' sanctuary environment in the ruins was shabby but warm: warm colors of oil lamps and candles, red collar and the decorative red five-pointed star, so that the war unveiled the mystery before it start.

\section{B. The Performance Authenticity of Decorative Color}

Decorative color can be used as an emotional factor to portrayed characters or plot in video works in order to get decorative and emotional unity, which is also one of the performance characteristics of decorative color.

"Red Sorghum" was the opening of the "Red Series "film directed by Zhang Yimou, the film used red as the main tone, almost all of the scenes revealed a layer of slightly red. The "Dian jiao" plot of the film was the most memorable plot for everyone, the vigorous and desolation "Jiaofu qu" among the sound of horns and suona will inspired your ears, and decorative color modeling language of Dianjiao all the way will made your eyes more excited: red velvet flowers, red scarf, red sedan-chair, red apron, red sorghum, red sorghum liquor, oily bronze back of the chair man, dark red sedan-chair passing through the turquoise sorghum, showered in the sunshine which dipped by red and yellow colors. A wild, witty, free and lively dance of life was playing in red and yellow tones. The same red and yellow tones, due to the different scenes and the changes of subjective emotion and subjective experience, the same color has different imagery characteristic and aesthetic implication. At the end of the film, when the wedding song played again: the explosion of red and yellow fire, thick black smoke, trembling blue sorghum leaves, the red Jiuer(actress of the film) fallen behind the yellow-white sun light, when she fell down to the floor, it splashed blood like "Shibali Hong", the passion, the shock, the color of blood in the Ascension the end of the film was red color which was too thick to dissolve and defuse, the red was glare and eye-catching; yellow sun looming in the swaying leaves of sorghum, copper cast guy standing like a mountain. They said: Death should be a pleasant thing and worth to die. In the last of the movie the use of red color was highly decorated and stylized, formed a shaping effect of decorative totem , the color use and setting of the film finished the subjective reflection of objective feelings of the characters, they were praised when they alive and were praised when they dead.

In the movie "Avatar", the use of decorative color in the whole film was always closely related to the main plot and main body, which the main colors have been changed between gray and fantasy blue. Director did not deliberately rendering anything but just use the decorative color to render and contrast the emotional atmosphere "moisten things silently". The audience will not forget the white soul tree, in Na'vi fantasy forest, only the soul tree was a large area of white, which is shrouded in mystery and holiness shining decorative white. It is associated with the audience's psychology, but also inseparable with people's common understanding and awareness of colors. White symbolizes peace, quiet, pure, holiness and hope, before the white soul tree appeared, it used a white tree fairy (soul tree seed) on several occasions as bedding. White glowing tree fairy like a beautiful angel, every time it appeared will triggered a change of the plot. The white soul tree was Na'vi's hope, is the last defense line of their beautiful home, they had confided their beautiful love under the tree and they had prayed for blessing under the tree. End of the film was like the expectation of audience, the Na'vi began a wonderful new life under the soul tree. Thus, though the decorative white color was not attracted attention as bright colors, but in the "Avatar" film, it had profound meaning, even the gray war smoke obscured the usual beauty of Pandora, but as long as the white soul tree was there, then the hope was there. White like a quiet song, though it did not have highpitched tone, but it implies a huge power, it sows the seeds of hope through war. From the foregoing, decorative color not only flatter the character in the video works, render the environment and background atmosphere, but more importantly is it could highlight the creator's unique, personalized conscious pursuit and role modeling.

\section{PRESENTATION MOdE OF DeCORATIVE COLOR IN VIDEO WORKS}

\section{A. The Balance of Decorative Color Layout}

The color change of decorative color in mobile lens which is change of shape and color saturation, and visual perception and psychological feelings presented to the audience's all reached a visual balance. It is more vivid than other visual presentation elements so it could control the overall balance of the work more directly. And this element contains certain "meaning" which plays an important role of being the character and image recognition.

Such as Zhang Yimou's film "The Flowers of war", the film's color can be summarized by two words "gorgeous decoration": colorful chi-pao and colorful decorative colors on the church windows, these dazzling decorative color features throughout the entire film. The gorgeous decorative costumes 
of "The Flowers of war" ostensibly in line with the true identity of the character design, actually was the exteriorization of the rich spiritual world for this group of women, and also made a strong color contrast with the graycolored city ruins which directly fit the film's English title "The Flowers of War". Heroine Yu Mo made appearance with her sisters in the opening, she wore dark blue leopard-print fur which matched with same color system purple chi-pao, her elegant temperament made a strong contrast with the church "no make-up" female students which implied the different fate of the two characters. Along with the development of the plot, $\mathrm{Yu}$ Mo's chi-pao change from bright red and blue peony into the sober dark green texture, revealed she both had impassioned, dare to love and hate nature, but also had wisdom and perseverance. When these women finally took off their luxuriant clothes and put on pure earth blue school uniforms, the decorative color changed from gorgeous into single, which implied inevitable fate of these thirteen beautiful flowers wither and fall. The close-up pictures of the gorgeous multicolored church windows were shot broken repeatedly was just a part of the long line of the film theme which emphasized the "gorgeous decoration" color was destroyed. As can be seen, Zhang Yimou's use of decorative color in this film was very metaphorical.

\section{B. The Symbolic Semantics of Decorative Color}

Decorative color plays an important symbolic role for characters, plot and emotion portrayal, through decorative color can express the creator's subjective intentions and ideas, and also through its symbolic effect it can make the audience aware of its atmosphere and the colors artistic conception relaxed.

Such as "Raise the Red Lantern", the red is a kind of symbolic symbol, red lantern as a decorative shape, it reinforced the color presentation in visual context. "It became a drama factor of the story development, it has close relationship with the fate of these women and the story development, if there is no 'Red Lantern' film's narrative will not be completed." First of all, red is a decorative symbolic color with all kinds of positive and negative passions. In the film, when the master of the house wants to go to one of his wife's room to sleep overnight, the butler will shout: light up the lantern of that wife's room. Red lantern has become a male-female relationship indicative, fascinating and exciting sex symbol. Second, the red lantern was a symbol of identity and status. When lighting or sealing the lantern became a color ceremony of Chen's grand Courtyard, the gold for the host and hostess of Chen's grand courtyard are "light up the lantern". Furthermore, red lantern referred to crazy or newborn, at the last part of the movie, red lantern light up again in third wife's room, but not as usual, this time the lantern was abnormally red. Song Lian torn down the dark blue hood of the lantern ; both for the third wife and herself for the first and last time light up the red lantern, this lighting up became a symbol of Song Lian's crazy or new life, which has completely different meaning with lighting up others lantern before.

Chen Kaige's "Farewell My Concubine" was also the same, Chen Dieyi's non male and non female image became eternal farewell. After our carefully taste, we found that director used a unique lens performance for on stage and off stage of Cheng Dieyi, which is mainly with close-up and close-range. Cheng Dieyi on stage as Bawang's Concubine, unusually brightly charming, at that time the decorative colors were dark blue, bright yellow, red and many other rich colors concentrated in her, the pouring down glittering tiara and gold thread embroidery red cape with yellow tassels made him became the King's only love on stage. But off the stage he was dispirited and negative because his deeply loved Shige failed to love him always, his swollen red eye makeup, pale face and red lips in the dark made extremely clear contrast, flattered his bored and heartbroken mood. Therefore, decorative colors in addition to be the important means to portray an objective object, it also could describe the story and express character's personalities through the lens utilization.

\section{Decorative Color Is A Combination of Reality and Exaggeration}

Decorative color also often with a strong sense of subjectivity and expression, use extremely exaggeration, sharp contrast and strong formal sense of color to express the theme, this reality and exaggeration unity is another performance characteristic of decorative color.

In the movie "Let the bullets fly", the opening scene was County magistrate Ma Bangde and his wife and private adviser Mr. Tang eating hot pot in "horses-pulled Train", in order to give the audience the impactive visual effects, the large pot was full of luxury golden color, and in the moment of the train turning and rise to the sky, the red drop fell on "Mafei"'s mask was not blood drop, it was actually a drop of hot pot soup, this bold exaggerated color decorated footage inside ideographic effects, successfully brought us into the absurd but real atmosphere.

The biggest feature of Ge You played fake private adviser Tang was difficult to distinguish sad and happy, extreme sadness immediately change into funny look, pathos suddenly superimposed in funny, and funny mocked the pathos, the taste was unspeakable complex, character performance was extremely exaggerated. In the movie, when adviser Tang came on the stage, the lens always with gorgeous exaggerated decorative colors in order to made stark contrast with the whole movie's pale yellow tone, it was difficult to distinguish sorrows and joys, complicated and changeable. When Huang Silang knew the whole truth, adviser Tang and Jiang Wen went to negotiate with Huang Silang, on the mobilization meeting which Huang Silang agreed to pay to suppress bandits, the background was bright red and also with some mechanical geometric decoration patterns. Red background here has played a effect for stimulating the atmosphere, it gave a funny, funny visual response to people, but this decorative red itself was a very brutal very bloody color, it implied the battle between Huang Silang and Jiang Wen really started, and also pushed the development of the whole story to a climax. During the suppress bandits battle, adviser Tang was killed, In order to revenged for the dead Liuzi, Laoer, County magistrate's wife and adviser Tang, Jiang Wen fought Huang Silang to the last drop of his blood. When the folks welcomed Jiang Wen back home, the whole color was the same bright red just like when they went to suppress the bandits, the red color here again 
pushed the story to a climax through the decorative context, which also was the last battle between justice and evil.

\section{CONCLUSION}

The study on decorative color, from narrow sense, is in particular image works through its decorative colors design and the overall re-design of relative color cultural connotation in order to effectively convey work emotions which will make audiences produce corresponding emotions by color suggestion. Broadly speaking, it is the new research formed by the development of modern society. It makes in-depth interpretation for the visual presentation of decorative color in the video works, it integrates the study into the thoughts of society, the results of science and technology, cultural heritage, to show the modern emotional appeal, which formed a "upward" visual art which related to the current popular culture and achieve the integration of personal interest and aesthetic pursuit.

\section{REFERENCES}

[1] "Art and Visual Perception" Rudolf Arnheim (Sichuan People's Publishing Company, 1998, 4th edition).

[2] "Film language" Marcel Mardan (China Film Press, 1980).

[3] "Film Aesthetics" Bela. Balazs (China Film Press 1982 1st edition).

[4] "Color psychology" Korean. Kim Yong-sook (People Post Press, 2010 edition).

[5] "Journal of Beijing Film Academy" 1st period in 2000

[6] "Artistic Conception" Zong Baihua (Peking University Press, 1999, 2nd edition).

[7] "Color aesthetics" Guo Lianfu (Shaanxi People's Fine Arts Publishing Company, 1992 edition).

[8] "Film Screen cinematography and creation" Zhang Huijun (China Film Press, August 1998 edition 1).

[9] "Film Chromatology" Liang Ming, Li Li (Peking University Press, 2008 August 1st Edition).

[10] "Introduction to Film Aesthetics" Jin Danyuan (Fudan University Press. 2008 Edition).

[11] "Introduction to Film Art Design" Zhou Dengfu (China Film Press, July 2007 Version 2).

[12] "Film and Television Art Design" Lv Zhichang (Beijing Broadcasting Institute Press, January 2001 edition).

[13] "Editing power" China Film Yearbook, China Film Press, July 2010 edition 1 . 